\title{
Resultados do Enade e Avaliação da Formação em Psicologia
}

\author{
Rômulo Travassos, Luciana Mourão ${ }^{1}$ \\ Universidade Salgado de Oliveira, Niterói-RJ, Brasil
}

RESUMO

O objetivo do estudo foi apresentar uma avaliação da formação em Psicologia a partir de uma análise documental dos resultados do Exame Nacional de Desempenho dos Estudantes nas edições 2006, 2009 e 2012. Os resultados contemplam 57.687 concluintes dos cursos de Psicologia e mostram aumento no percentual de estudantes que participam de atividades de iniciação científica, monitoria e extensão em contraposição a um decréscimo das notas médias no componente geral e, sobretudo, no componente específico das provas (caindo de 52,7 em 2006 para 37,6 em 2012). Chama a atenção o fato de o desempenho dos estudantes, ao longo desses anos, ter caído mais nas instituições de ensino superior públicas do que nas instituições privadas. Esses resultados denunciam muitas fragilidades na formação do psicólogo no Brasil e devem servir de alerta para todos aqueles que atuam no ensino da Psicologia e também para as instituições representativas da categoria.

Palavras-chave: competências, exame nacional de desempenho dos estudantes - ENADE, formação em psicologia.

\section{ABSTRACT - Results of the ENADE and an Assessment of Academic Training in Psychology}

The objective of the study was to present an evaluation of Psychology education based on a documentary analysis of National Student Performance Examination (ENADE) results in the 2006, 2009 and 2012 editions. Results include 57,687 Psychology course graduates and show an increase in the percentage of students participating in scientific initiation, monitoring and extension activities, but also a decrease in average scores in the exam's general components and, markedly, on the specific component (falling from 52.7 in 2006 to 37.6 in 2012). It is striking that the performance of students over these years has fallen more in public higher education institutions than in private institutions. These results denounce many weaknesses in Brazilian Psychology education and should serve as an alert for those involved in teaching Psychology, as well as to the institutions representing the category.

Keywords: Competencies; National Student Performance Exam - ENADE; Psychology education.

\section{RESUMEN - Resultados del ENADE y evaluación de la Formación en Psicología}

El objetivo del estudio fue presentar una evaluación de la formación en Psicología, a partir de un análisis documental de los resultados del Examen Nacional de Desempeño de los Estudiantes en las ediciones 2006, 2009 y 2012, ENADE. Los resultados contemplan a 57.687 individuos que culminaron los cursos de Psicología y muestran aumento en el porcentaje de estudiantes que participan de actividades de iniciación científica, monitoreo y extensión, en contraposición a una disminución de las notas medias en el componente general y, principalmente en el componente específico de las pruebas (disminuyendo de 52,7 en 2006 para 37,6 en 2012). Llama bastante la atención, el hecho de que el desempeño de los estudiantes a lo largo de esos años, disminuyó más en las instituciones de enseñanza superior pública que en las instituciones privadas. Esos resultados denuncian muchas fragilidades en la formación de psicólogos en Brasil y deben servir de alerta para todos aquellos que actúan en el campo de enseñanza de Psicología como también para las instituciones representativas de la categoría.

Palabras-clave: Competencias; Examen Nacional de Desempeño de los Estudiantes - ENADE; Formación en Psicología.

\section{Introdução}

No início do século XXI, a Educação Superior brasileira tem passado por mudanças em sua configuração e funcionamento, com destaque para a abertura de novas Instituições de Ensino Superior - IES e processos de diferenciação, desregulamentação e privatização da oferta e financiamento (Souza, 2012), assim como um expressivo aumento de vagas na rede pública (Saviani,
2011), sobretudo em função do Programa de Apoio a Planos de Reestruturação e Expansão das Universidades Federais Brasileiras - Reuni (Lima \& Machado, 2016).

Nesse contexto de expansão do ensino superior, ganha destaque a avaliação dos cursos, regida pela Lei do Sistema Nacional de Avaliação da Educação Superior Sinaes (Lei ${ }^{\circ}$. 10.861/2004). A referida lei regulamenta a avaliação das IES, os cursos e o desempenho dos alunos, por meio do Exame Nacional de Desempenho dos 
Estudantes - Enade, que começou a ser aplicado em 2004, contemplando o desempenho de alunos ingressantes e concluintes e, em 2010, passou a contemplar somente alunos concluintes.

De acordo com o artigo $5^{\circ}$, parágrafo $1^{\circ}$, da Lei 10.861/04, o Enade avalia "o desempenho dos estudantes em relação aos conteúdos programáticos previstos nas diretrizes curriculares do respectivo curso de graduação, suas habilidades para ajustamento às exigências decorrentes da evolução do conhecimento e suas competências para compreender temas exteriores ao âmbito específico de sua profissão, ligados à realidade brasileira e mundial e a outras áreas do conhecimento".

Por um lado, há manifestações contrárias ao Enade, sobretudo, em função de a avaliação ser classificatória/regulatória do sistema de ensino, resultando em um "rankeamento" dos cursos (Castro, 1995; Tavares, Oliveira, \& Seiffert, 2011). Por outro, há a ponderação de que o Enade adota uma visão emancipatória e formativa da avaliação da Educação Superior (Fiamini \& Calderón, 2012), sendo reconhecidos o seu objetivo de identificar habilidades e competências de universitários (Molck \& Calderón, 2014) e os seus reflexos sobre a vida, o projeto e os interesses das instituições, particularmente, sobre o padrão organizativo-funcional do sistema de educação de nível superior em geral (Gomes, 2002).

O mapeamento realizado por Molck e Calderón (2014) das dissertações de mestrado e teses de doutorado relativas ao Enade, produzidas de 2004 a 2010, conclui que os estudos sobre o Enade se distanciam das discussões de componentes ideológicos e focalizam mais aspectos técnico-operacionais, compreendendo impactos e estratégias de aprimoramento no âmbito institucional, bem como estratégias didático-pedagógicas no campo da aprendizagem e do desempenho dos estudantes.

O exame é organizado a partir da avaliação de dois componentes - o de formação geral, comum aos cursos de todas as áreas, e o componente específico para cada curso. A prova de formação geral considera como elementos integrantes do perfil profissional: letramento crítico; atitude ética; comprometimento e responsabilidade sociais; compreensão de temas que transcendam ao ambiente próprio de sua formação, relevantes para a realidade social; espírito científico, humanístico e reflexivo; capacidade de análise crítica e integradora da realidade; e aptidão para socializar conhecimentos com públicos diferenciados e em vários contextos (Instituto Nacional de Estudos e Pesquisas - Inep, 2015). O componente de conhecimento específico do Enade é voltado para as diretrizes curriculares e está mais diretamente associado à competência profissional, que diz respeito à capacidade de articulação dos conhecimentos adquiridos e sua eficácia nas atividades solicitadas pela natureza do trabalho (Brito, 2008; Vendramini \& Lopes, 2016).

Para a composição da nota final, o componente específico contribui com $75 \%$ e a formação geral com
$25 \%$, conforme o total de questões nas provas (Inep, 2015). O Enade avalia, então, uma série de competências acadêmicas e habilidades profissionais com respaldo dos conhecimentos previstos nas Diretrizes Curriculares Nacionais relativas a cada curso de graduação. Destarte, o Exame permite aferir o desenvolvimento de competências profissionais singulares de cada área, assim como o desempenho em questões transdisciplinares (Primi, Hutz, \& Silva, 2011).

A nota obtida pelos alunos não é divulgada e não apresenta qualquer implicação direta para os participantes, pois o foco da avaliação se volta para as IES, numa lógica de avaliação de cursos, iniciada nos anos 1990 com o antigo Provão (Embiruçu, Fontes, \& Almeida, 2010). Assim, o desempenho dos estudantes compõe o Conceito Preliminar de Curso (CPC), um indicador de qualidade regulador da renovação de reconhecimento dos cursos de graduação.

O exame possibilita aos cursos o acompanhamento dos resultados de suas ações pedagógicas, ao tempo em que avalia comparativamente a formação oferecida pelas IES aos estudantes de diferentes áreas, sem preocupação com a ênfase de cada curso. É responsabilidade do avaliador de curso, na visita in loco, fazer análise da compatibilização que há entre a ênfase, a realidade social e o perfil do profissional formado pela IES (Souza, Bastos, \& Barbosa, 2011). O Enade focaliza, pois, a avaliação dos alunos relativamente aos vários temas que dão forma às diretrizes curriculares do curso, caracterizando-se avaliação para a aprendizagem e não apenas avaliação da aprendizagem (Brito, 2008). Dessa maneira, o Enade consiste em um mecanismo de avaliação com o propósito de realizar um diagnóstico de competências e habilidades dos estudantes no decorrer dos anos de graduação, objetivando medir o conhecimento agregado ao aluno, pelo curso (Verhine, Dantas, \& Soares, 2006).

Diante do exposto, é fato que o Enade adquiriu, nos últimos anos, centralidade e importância institucional e governamental (Santos et al., 2016; Tavares et al., 2011). O Exame ocorre em um ciclo trienal de avaliação, com as áreas de formação subdivididas em três grupos que se alternam em anos subsequentes. Os cursos de Psicologia foram avaliados em 2006, 2009, 2012 e 2015, sendo que os resultados do último ano ainda não foram disponibilizados pelo INEP. Souza et al. (2011) analisaram os resultados obtidos pelos estudantes ingressantes e concluintes que realizaram o Enade-2006 em Psicologia quanto a dados socioeconômicos, de história escolar e componentes específicos do conhecimento psicológico. Os resultados mostram, no geral, as deficiências da formação, com destaque para os fundamentos históricos, epistemológicos, metodológicos, investigação, medidas e uma supremacia nas notas das IES federais e estaduais, no tocante ao desempenho. Contudo, os indicadores parecem ter mudado bastante nos anos seguintes (INEP, 2015). 
Assim, o objetivo do presente estudo é avaliar a formação em Psicologia a partir dos resultados do Enade nas edições 2006, 2009 e 2012. Para tanto, adotou-se a metodologia de análise documental dos relatórios do Enade nas três edições disponíveis no sítio eletrônico do Inep, contemplando os dados dos componentes gerais e específicos em cada ano de avaliação, conforme descrito a seguir.

\section{Método}

Esta é uma pesquisa de análise documental, que contempla os resultados do Enade para o curso de Psicologia, fundamentando-se nos relatórios das edições do exame realizadas nos anos de 2006, 2009 e 2012. Os três relatórios que deram origem às presentes análises estão disponíveis no sítio eletrônico do Inep (http:// portal.inep.gov.br/web/guest/relatorios).

A proposta foi realizar uma análise da evolução dos cursos de Psicologia em termos de desempenho no Exame, comparando os dados de instituições públicas e privadas e de diferentes regiões do país. Foram analisados os resultados relativos à prova de conhecimentos gerais e específicos nas três edições do exame, a fim de identificar possíveis tendências relativas à avaliação da formação em Psicologia.

Uma vez que, a partir de 2010, a prova do Enade passou a contemplar especificamente os alunos concluintes e considerando que o objetivo do presente estudo era avaliar a formação em Psicologia a partir dos resultados do Enade, optou-se por analisar neste trabalho somente os dados relativos aos alunos concluintes.

No que diz respeito aos aspectos que serão avaliados no presente artigo, considerou-se três distintos instrumentos adotados no Enade, a saber: (a) os testes, compostos por questões discursivas e de múltipla escolha; (b) questionário com o objetivo de conhecer a percepção dos alunos sobre o teste; (c) questionário socioeconômico-educacional do aluno, de preenchimento voluntário. Cada um desses instrumentos ofereceu diferentes informações acerca da formação em Psicologia no período de 2006 a 2012.

Por fim, para permitir uma análise comparativa dos resultados obtidos pela Psicologia nos componentes geral e específico ao longo dos anos com os resultados obtidos por outras áreas, optou-se por avaliar os relatórios de todos os cursos que tiveram avaliação nas edições do Enade dos anos de 2006, 2009 e 2012, quais sejam: Administração, Ciências Contábeis, Ciências Econômicas, Comunicação Social, Design, Direito, Psicologia, Secretariado Executivo e Turismo. Os resultados obtidos são apresentados e discutidos a seguir.

\section{Resultados e Discussão}

A partir de 2006, os cursos de Psicologia no país passaram a ser avaliados pelo Enade. Desde a primeira edição até 2012, o número de alunos concluintes totalizou 57.687, com uma média de aproximadamente 19 mil alunos de Psicologia em cada edição do Exame. Em termos do número de instituições de ensino avaliadas, a média foi de 380 instituições, com variabilidade baixa nos anos de 2006, 2009 e 2012.

$\mathrm{Na}$ distribuição regional das IES, destaca-se a região Sudeste com o maior número de estudantes concluintes nas três edições do Enade. Contudo, essa concentração regional teve uma gradativa redução, pois a porcentagem de concluintes em 2006 era de 57\% e, nas duas edições seguintes esse percentual caiu para $53 \%$ e $48 \%$, respectivamente. Por outro lado, a região Nordeste foi a que teve maior ganho percentual de alunos de Psicologia, pois o percentual de concluintes dessa região se elevou de $11 \%$, em 2006, para 19\%, em 2012. As regiões Norte e Sul tiveram um ligeiro incremento em seus percentuais (entre 1\% e 3\%) de alunos concluintes na comparação dos anos de 2006 e 2012. A região Centro-Oeste, contudo, teve um decréscimo no percentual de concluintes que era de $11 \%$, em 2006 , passou para $9 \%$, em 2009 , e atingiu o patamar de $8 \%$, em 2012, conforme pode ser visto na Tabela 1 .

Os resultados sobre a expansão das IES e aumento da população concluinte no Nordeste estão associados a políticas públicas de descentralização das vagas na região Sudeste, com aumento de ofertas nas universidades públicas e no setor privado nas últimas décadas (Bertolin, 2009). A rede privada se expandiu em um contexto de diversificação e diferenciação das instituições e das políticas de avaliação do Governo Federal para dar continuidade ao Programa Universidade para Todos - Prouni (Polidori, Marinho-Araújo, \& Barryero, 2006).

Assim é que, apesar de o Governo ter investido na criação de novas universidades públicas e de mais vagas nas universidades federais já existentes, o expressivo aumento nos investimentos do Fundo de Financiamento Estudantil - Fies contribuiu para ampliar as matrículas na rede privada (Silva \& Silva, 2009). Isso ajuda a explicar um percentual mais alto de IES privadas e dos concluintes no Nordeste na edição de 2012 em relação às outras regiões.

$\mathrm{O}$ fato de o número de concluintes no Nordeste ter quase dobrado, enquanto o aumento do número de IES na Região cresceu 27,5\%, indica que houve mais abertura de vagas nas instituições já existentes do que em novas IES. Já a redução de $17,3 \%$ no número de IES no Sudeste pode ser consequência da regulação do sistema, que inclui o credenciamento e recredenciamento de instituições, autorização, reconhecimento e renovação de reconhecimento dos cursos, que pode ter resultado no descredenciamento de instituições com base nos resultados do ENADE (Tavares et al., 2011).

Em relação ao desempenho dos estudantes concluintes do curso de Psicologia nas provas do Enade, observou-se que as médias tendem a ser baixas e que, lamentavelmente, encontram-se em um processo decrescente tanto 
no componente de formação geral quanto no componente e específico. Os resultados da média de formação geral da prova de Psicologia foram 47,2 pontos em 2006; elevou-se um pouco para 48,7 em 2009 e caiu para 42,1 pontos em 2012. E os valores tendem a ser ainda mais baixos no componente de formação específica. As médias nesse componente foram de 52,7 pontos em 2006; passaram para 46,7 em 2009 e chegou a 37,6 pontos em 2012 (Figura 1). Esse é um patamar muito baixo e bastante preocupante na medida em que sinaliza para um desenvolvimento medíocre de competências profissionais nos concluintes do curso de Psicologia no país.

Tabela 1

Distribuição por Região das IES e dos Alunos de Psicologia nas Três Edições do Enade

\begin{tabular}{|c|c|c|c|c|c|c|c|}
\hline & \multirow{2}{*}{ Regiões } & \multicolumn{2}{|c|}{ ENADE 2006} & \multicolumn{2}{|c|}{ ENADE 2009} & \multicolumn{2}{|c|}{ ENADE 2012} \\
\hline & & $n$ & $\%$ & $n$ & $\%$ & $n$ & $\%$ \\
\hline \multirow{6}{*}{ IES } & Total Brasil & 373 & $100 \%$ & 396 & $100 \%$ & 371 & $100 \%$ \\
\hline & Norte & 18 & $5 \%$ & 29 & $7 \%$ & 27 & $7 \%$ \\
\hline & Nordeste & 51 & $14 \%$ & 67 & $17 \%$ & 65 & $18 \%$ \\
\hline & Sudeste & 198 & $53 \%$ & 176 & $44 \%$ & 163 & $44 \%$ \\
\hline & Sul & 80 & $21 \%$ & 93 & $23 \%$ & 87 & $23 \%$ \\
\hline & Centro-oeste & 26 & $7 \%$ & 31 & $8 \%$ & 29 & $8 \%$ \\
\hline \multirow{6}{*}{$\begin{array}{l}\text { População } \\
\text { concluinte }\end{array}$} & Total Brasil & 19.165 & $100 \%$ & 17.931 & $100 \%$ & 20.591 & $100 \%$ \\
\hline & Norte & 927 & $5 \%$ & 701 & $4 \%$ & 1.169 & $6 \%$ \\
\hline & Nordeste & 2.040 & $11 \%$ & 2.794 & $16 \%$ & 3.993 & $19 \%$ \\
\hline & Sudeste & 11.014 & $57 \%$ & 9.522 & $53 \%$ & 9.965 & $48 \%$ \\
\hline & Sul & 3.043 & $16 \%$ & 3.359 & $19 \%$ & 3.916 & $19 \%$ \\
\hline & Centro-oeste & 2.141 & $11 \%$ & 1.555 & $9 \%$ & 1.548 & $8 \%$ \\
\hline
\end{tabular}

Nota. Dados extraídos dos relatórios do Inep/Sinaes/Enade (2006, 2009 e 2012)

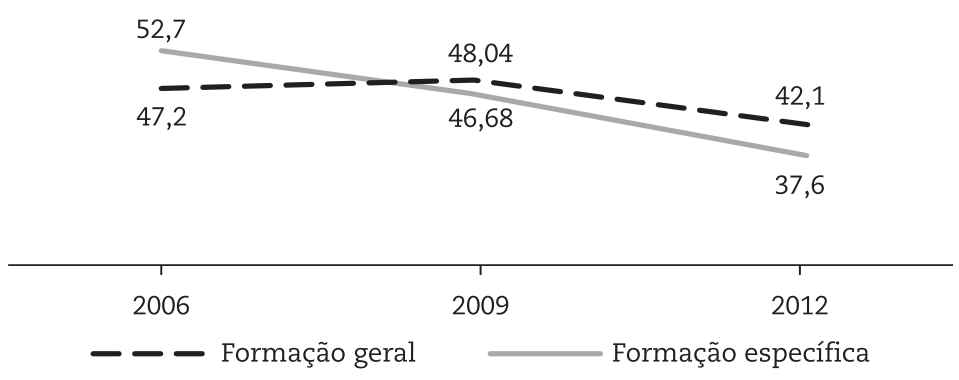

Figura 1. Notas médias da formação geral e específica em Psicologia nas edições do Enade

Os indicadores tão baixos de desempenho e a expressiva queda da pontuação nos componentes geral e específico da prova levaram ao questionamento se essa baixa de qualidade é peculiar aos cursos de Psicologia ou se é um fenômeno que está assolando à Educação Superior como um todo. Para permitir essa análise, foi feita uma comparação dos resultados da Psicologia com todos os demais cursos avaliados nas edições de 2006, 2009 e 2012 do Enade.

Os resultados apontam para médias também baixas no componente geral e específico de outros cursos. Por exemplo, os cursos de Administração, Ciências Contábeis, Ciências Econômicas e Comunicação Social foram os que mais demonstraram desempenho baixo, em média, 40,0 nas três edições do exame, sendo Ciências
Contábeis com menor desempenho no componente geral com 38,7, em 2009, e, no específico, com a média 25,7, em 2006. Os cursos de Turismo, Design e Direito possuem médias mais altas que 40,0, mesmo assim, estão abaixo da média de 50,0. Essa semelhança nos desempenhos dos diferentes cursos fica evidenciada quando se compara as notas médias da Psicologia com as notas médias do conjunto dos cursos que participaram das mesmas edições do Enade. Contudo, o decréscimo de notas no curso de Psicologia foi superior ao conjunto dos demais cursos. Em 2006, as médias da Psicologia, em ambos os componentes, estavam acima do conjunto dos cursos, com destaque para o desempenho da área no componente específico (48,7 pontos) que era bem superior à média 
dos demais (39 pontos). Em 2012, essa realidade mudou. As notas da Psicologia nos componentes geral (42,1 pontos) e específico $(37,6)$ ficaram ligeiramente abaixo das médias do conjunto dos cursos, respectivamente 42,6 e 37,9 pontos. A Tabela 2 detalha os resultados obtidos por cada um dos cursos avaliados em 2006, 2009 e 2012.

Tabela 2

Desempenho dos Cursos Aualiados no Enade nas Edições de 2006, 2009 e 2012

\begin{tabular}{|c|c|c|c|c|c|c|}
\hline \multirow[b]{2}{*}{ Curso } & \multicolumn{2}{|c|}{2006} & \multicolumn{2}{|c|}{2009} & \multicolumn{2}{|c|}{2012} \\
\hline & $\begin{array}{c}\text { Comp. } \\
\text { geral }\end{array}$ & $\begin{array}{l}\text { Comp. } \\
\text { espec. }\end{array}$ & $\begin{array}{c}\text { Comp. } \\
\text { geral }\end{array}$ & $\begin{array}{l}\text { Comp. } \\
\text { espec. }\end{array}$ & $\begin{array}{c}\text { Comp. } \\
\text { geral }\end{array}$ & $\begin{array}{l}\text { Comp. } \\
\text { espec. }\end{array}$ \\
\hline Administração & 44,1 & 41,3 & 39,1 & 37,5 & 42,9 & 31,9 \\
\hline Ciências Contábeis & 44,1 & 25,7 & 38,7 & 30,4 & 39,4 & 32,8 \\
\hline Ciências Econômicas & 45,4 & 31,2 & 47,9 & 31,6 & 43,3 & 27,0 \\
\hline Comunicação Social & 47,6 & 37,9 & 42,1 & 47,0 & 40,7 & 36,9 \\
\hline Design & 48,1 & 46,1 & 46,5 & 46,6 & 42,3 & 47,0 \\
\hline Direito & 48,2 & 35,5 & 46,4 & 46,8 & 46,0 & 39,1 \\
\hline Psicologia & 47,2 & 48,7 & 48,0 & 52,7 & 42,1 & 37,6 \\
\hline Secretariado Executivo & 44,4 & 38,7 & 40,0 & 41,6 & 42,4 & 47,4 \\
\hline Turismo & 49,7 & 45,6 & 44,1 & 55,2 & 44,2 & 41,3 \\
\hline
\end{tabular}

Nota. Dados extraídos dos relatórios do Inep/Sinaes/Enade (2006, 2009 e 2012)

Se for feita uma análise do desempenho dos concluintes do curso de Psicologia por região, observa-se que a região Norte obteve a média mais baixa no componente específico $(35,7)$, enquanto a região Sul, a média mais alta 41,1. Contudo, em todo o Brasil, as notas tendem a ser baixas (bastante inferiores ao ponto médio da escala, que seria de 50 pontos), indicando lacunas no desenvolvimento das competências profissionais do Psicólogo no Brasil (Abbad \& Mourão, 2010).

Ao analisar os resultados do desempenho do componente geral, percebeu-se que as instituições públicas foram melhores em comparação às particulares nas edições de 2006 e 2009. No entanto, observou-se uma significativa diferença nas médias da edição de 2012, com desempenho superior da rede privada $(39,1) \mathrm{em}$ comparação com as IES públicas (36,6) (INEP, 2015), o que modifica o cenário traçado por Souza et al. (2011) acerca do desempenho superior das IES públicas nos cursos de Psicologia. Os relatórios mostraram que, ao longo dos processos, os alunos das instituições públicas foram superiores, porém o decréscimo de desempenho nos últimos anos foi maior na rede pública. Apesar de as notas médias no componente específico mostrarem que os alunos das instituições públicas estão com desempenho inferior ao das instituições privadas, no quesito distribuição dos conceitos, as IES públicas foram melhores do que as privadas em todas as edições do exame. Apesar de as IES públicas corresponderem a mais de $80 \%$ do conjunto das instituições, em 2012, das que receberam o conceito 5 (nota máxima no exame), nove eram públicas e apenas cinco privadas.

Quanto às questões discursivas do componente geral, as notas médias por edição sofreram uma vertiginosa queda, partindo de 49,4 em 2006, baixando para 37,3 em 2009 e ficando abaixo de 20 pontos em 2012. Uma queda tão brusca nessas notas deixa uma reflexão se teria havido um aumento gradativo na complexidade e grau de dificuldade das questões ou se houve, de fato, uma queda na aquisição de competências, incluindo a capacidade de análise e argumentação dos concluintes do curso de Psicologia.

As questões discursivas do componente específico também apresentaram resultados preocupantes. Em 2006, a nota média dos concluintes foi de 25,8; em 2009, subiu para 27,92 e, em 2012, a média foi mais baixa, 19,8. Além disso, tais questões têm mostrado a ocorrência de respostas do senso comum, com baixa coerência, pouco domínio de conteúdo e deficiência em interpretar e argumentar, além de dificuldades nas habilidades com a língua portuguesa, com elevado percentual de erros gramaticais e ortográficos e dificuldades na estruturação argumentativa da resposta (INEP, 2015).

Assim, os resultados das questões objetivas e discursivas do exame, tanto do componente geral, quanto no componente específico da Psicologia apontam para lacunas na aprendizagem dos estudantes. Estaria esse decréscimo nas notas dos estudantes associado à rápida e desordenada expansão dos cursos de graduação, especialmente, a partir da década de 1990, conforme sinalizado por Lisboa e Barbosa (2009)? É preciso considerar que Souza et al. (2011) já apontavam para uma fragilidade no desempenho dos discentes visível nos três eixos da sua formação básica: investigação e medidas (voltado para a formação científica), interfaces (que articula os conhecimentos da Psicologia com as ciências biológicas e humanas) e, também, fundamentos históricos 
e epistemológicos. Se os formandos não dominam tais eixos, conclui-se que a deficiência cobre as dimensões básicas estabelecidas pelas diretrizes curriculares.

Quanto ao quesito percepção sobre a prova, no INEP (2015), 23\% dos estudantes concluintes consideraram que a prova do componente geral foi difícil/ muito difícil. Na edição do exame em 2009, o percentual que considerou a prova difícil/muito difícil aumentou para $29 \%$ e, em 2012, em coerência com a redução das notas gerais no Enade, a percepção dos estudantes concluintes de que a prova estava difícil/muito difícil se elevou para $35,8 \%$.

Analisando as respostas sobre o grau de dificuldade da parte relativa ao componente específico, percebeu-se que, em 2006, o percentual de que a prova estava difícil/ muito difícil foi de $28 \%$, em 2009 e 2012, esse percentual foi, respectivamente, de $42 \%$ e $41 \%$. Tais resultados sinalizam para um aumento no nível de dificuldade das provas ou para uma maior deficiência na formação dos psicólogos, nesse último caso, o cenário é preocupante na medida em que esses são os profissionais que irão atuar nas diversas áreas da Psicologia. Como a prova de conhecimentos específicos do Enade é montada a partir das diretrizes curriculares definidas para o curso, o resultado aponta para lacunas na formação que podem afetar a qualidade do trabalho que a categoria profissional dos psicólogos prestará para a sociedade.

Vale considerar que, embora a avaliação se refira ao desempenho do estudante, os resultados observados constituem um meio para se avaliar a qualidade do curso (Primi et al., 2011). Portanto, em última instância, as inferências são feitas sobre a qualidade dos cursos ofertados pelas diferentes IES, o que permite uma análise também nesse nível macro.

Essa discussão relaciona-se às reflexões de Brito (2008) de que as concepções e princípios no âmbito do Sinaes articulam a avaliação dos cursos à avaliação institucional. Assim, a avaliação da formação acadêmica e profissional deve ser entendida como uma atividade apreciativa da qualidade do curso no contexto da realidade institucional, independentemente de qual esfera a IES pertence, uma vez que o exame constitui um ato formal de testemunho de fé pública a respeito dos resultados alcançados pelo curso com base em critérios e padrões externos e previamente estabelecidos (Brito, 2008).

A comparação da formação nas esferas pública e privada mostra que, embora tradicionalmente o desempenho das universidades públicas seja superior, as universidades privadas tiveram, em 2012, um desempenho ligeiramente maior ao das públicas em 2012. Nas edições anteriores, nenhuma das IES privadas tinha obtido o conceito máximo (5) no exame. Não se pode negar que a avaliação externa e padronizada leva a um "rankeamento", favorecendo um modelo mercantil da Educação Superior no país. Para Bertolin (2009), dentre as principais justificativas para a ampliação da mercantilização, está o argumento de que a competição de mercado induz à inovação e à adaptação dos sistemas às novas necessidades. Bertolin pondera, contudo, que aqueles que defendem o princípio da Educação Superior como bem público visam a uma formação de qualidade, com o objetivo de atender às necessidades do mercado em qualquer âmbito que esses profissionais viessem a atuar. Contudo, não se pode negar que a Educação Superior no Brasil está fundamentalmente nas mãos das IES privadas, uma vez que, mais de três quartos dos alunos estão matriculados nessas instituições.

No que diz respeito ao acesso à informação, em 2006, 75,5\% dos estudantes concluintes em Psicologia afirmava ir frequentemente ou muito frequentemente às bibliotecas das IES. A Internet nessa primeira avaliação já estava em destaque na formação dos alunos como fonte de pesquisa para trabalhos acadêmicos e também como fonte de informações sobre o mundo contemporâneo, mas foi ganhando maior espaço nos exames seguintes. Em 2009, muitos estudantes (22,6\%) afirmaram utilizar a biblioteca apenas em épocas de provas e/ou trabalhos, enquanto um contingente expressivo $(63,3 \%)$ afirmava utilizar a biblioteca pelo menos uma vez por semana. Em 2012, os que utilizam a biblioteca pelo menos uma vez por semana passaram a ser $24,4 \%$ para trabalhos, provas e pesquisa. Segundo o INEP (2015), as bibliotecas universitárias devem prover um acervo mínimo para possibilitar o acesso dos estudantes à bibliografia, além do material instrucional utilizado pelo curso, sistema de empréstimo de livros e periódicos ligados à sede da IES.

Quanto à participação em atividades extraclasse, os dados mostram uma evolução ao longo das edições do Enade, sobretudo em termos de atividades de monitoria e de extensão promovidas pela instituição. Em 2006, apenas $7,9 \%$ dos estudantes afirmavam ter participado de atividades de monitoria. Em 2009, esse número saltou para $22,2 \%$ e, em 2012, cresceu um pouco mais, atingindo um quarto dos concluintes do curso de Psicologia. A participação em atividades de extensão, por sua vez, partiu de um patamar mais alto que a monitoria em 2006, pois, naquela época, $22,5 \%$ dos estudantes já afirmavam ter participado de atividades de extensão ofertadas por sua instituição. Em 2009, esse número cresceu para 43,2\% e, em 2012, atingiu o patamar de 49,6\%, o que indica que metade dos estudantes participaram de atividades de extensão durante a sua graduação.

Em termos das atividades relacionadas à pesquisa, em 2006 o questionário do Inep distinguiu os alunos que participavam de iniciação científica ou tecnológica $(10,4 \%)$ daqueles que atuavam em projetos de pesquisa conduzidos por professores da IES $(21,7 \%)$. Mas, se consideradas em conjunto, cerca de um terço dos concluintes tiveram a oportunidade de participar de atividades dessa natureza. Em 2009, esse percentual se elevou para $37,5 \%$ e, em 2012, manteve-se no patamar de 38,2\%. 
Portanto, houve um ligeiro acréscimo na participação em atividades ligadas à pesquisa no período de 2006 a 2012. A
Figura 2 mostra a evolução da participação nas atividades extraclasse ao longo dos anos.

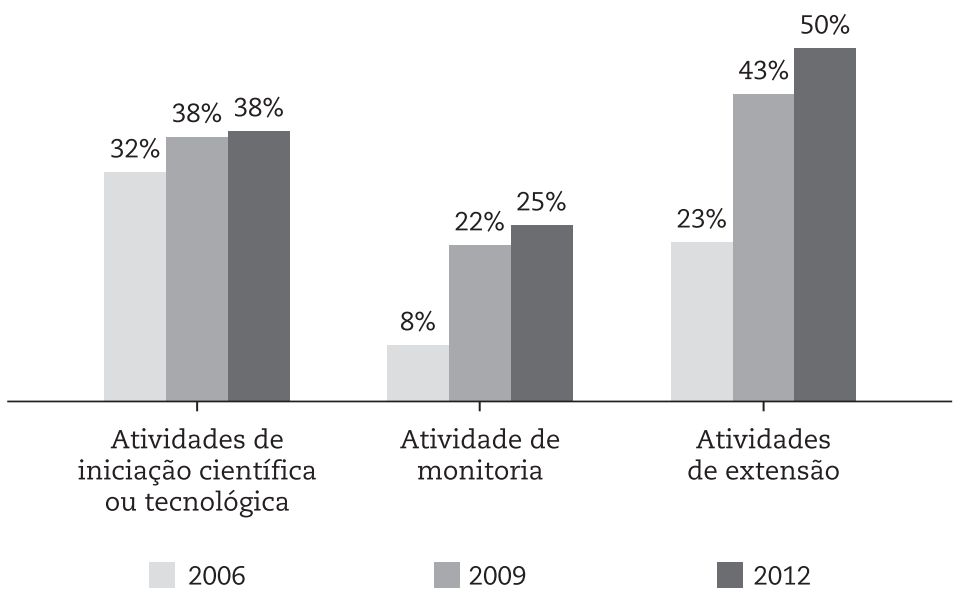

Figura 2. Evolução do percentual de participação em atividades extraclasse

Esses dados relativos à participação em atividades extraclasse são importantes tendo em vista que os pilares da Educação Superior estão baseados na sinergia das atividades de ensino, pesquisa e extensão. Guareschi, Wendt e Dhein (2011) analisaram os resultados da edição 2006 do Enade em Psicologia e concluíram que o intercâmbio entre a graduação e a pós-graduação era pouco efetivo e que as atividades de monitoria ainda eram predominantes entre os alunos das instituições federais. Nas edições seguintes, essa realidade foi se modificando, com um expressivo aumento na participação das atividades extraclasse, em especial, nas atividades de monitoria e de extensão.

Vale ainda destacar que a relação entre a participação em tais atividades e a melhoria da formação é percebida pelos estudantes, conforme constata o relatório do Enade de 2012, que incluiu não só os percentuais de participação, mas também a avaliação que os estudantes faziam da contribuição de cada uma dessas atividades. De acordo com tal relatório, dentre os que participaram das atividades de iniciação científica, 83\% considera que tal participação teve grande contribuição para a sua formação. Para as atividades de monitoria e extensão esse percentual foi respectivamente de $83,7 \%$ e $88,5 \%$.

Mas a despeito da elevação do percentual de participação em atividades extraclasse, do reconhecimento dos estudantes da contribuição de tais atividades para a sua formação e das reflexões de que tais atividades contribuem para o aperfeiçoamento da qualidade acadêmica (Polidori et al., 2006), o desempenho dos estudantes nas edições do Enade tem sido decrescente, sobretudo no componente específico da prova. Isso fortalece a recomendação feita no relatório do Inep, relativamente aos resultados do Enade em Psicologia de 2012, de que os cursos precisam se adequar para oferecer um ensino de qualidade (INEP, 2015). O relatório também enfatiza a necessidade de se trabalhar a percepção do estudante quanto à concepção do curso no que se refere a articular o conhecimento da área com aspectos sociais, políticos e culturais da realidade brasileira e com temas gerais e situações do cotidiano.

Isso significa não apenas a IES proporcionar as atividades extraclasses, como pesquisa, extensão e monitoria - como foi expressamente recomendado no relatório (INEP, 2015), mais também, acompanhar esse alunado por meio da orientação e capacitação em oficinas e aprofundamento da metodologia da Pesquisa. Uma forma de atingir esse objetivo é promover os grupos de estudo, orientar os alunos a aplicar projetos com a comunidade, relatar e discutir essas atividades em sala de aula.

Quanto às características socioeconômicas dos estudantes, a pesquisa com os participantes do Enade mostra que, em 2006, os que se classificavam como brancos correspondiam 69,9\% da amostra. Em 2009, esse percentual reduziu para $67 \%$ e, em 2012, manteve-se em $66,5 \%$. Portanto, apesar de ter havido um ligeiro aumento na participação de estudantes que se declararam como pardos(as)/mulatos(as), negros(as), ou de origem indígena, ainda há uma desproporção elevada na distribuição étnica nos cursos de Psicologia, uma vez que o percentual da população que se autodeclarou como branca no último Censo Demográfico de 2010 foi de 47,7\% (Instituto Brasileiro de Geografia e Estatística - IBGE, 2012).

Os resultados de etnia encontram forte relação com a variável renda familiar, uma vez que os estudantes de Psicologia apresentam um perfil de renda relativamente 
elevado. Em 2006, o percentual de concluintes cuja renda familiar era superior a dez salários mínimos era de 38\%. Em 2009 e em 2012, esse percentual caiu bastante (respectivamente para $24,4 \%$ e $16,3 \%$ ). Tal redução pode estar relacionada a políticas públicas de democratização do acesso ao ensino superior, de forma a contribuir para uma mudança no perfil dos egressos, no sentido de diminuir o caráter elitista, algumas vezes associado à profissão (Puente-Palacios, Abbad, \& Martins, 2010). Além disso, também é preciso considerar a mudança do cenário socioeconômico do país que aponta para ganhos reais do salário mínimo no período de 2006 a 2012.

Quanto ao gênero, ainda há uma predominância de estudantes mulheres, pois, no relatório do Enade 2012, observa-se que $83,4 \%$ dos participantes eram mulheres. Esse percentual está em consonância com a pesquisa realizada pelo CFP em 1980 que identificou que $86,6 \%$ de mulheres atuando na área (Conselho Federal de Psicologia [CFP], 1988) e com a pesquisa de Bastos, Gondim e Rodrigues (2010), que apontaram um percentual de 83,3\% na amostra nacional de psicólogos no Brasil; ou de Yamamoto, Falcão e Seixas (2011) em cuja pesquisa, $84,1 \%$ dos estudantes de Psicologia eram mulheres. Portanto, reafirma-se a característica feminina da profissão.

\section{Considerações Finais}

O presente estudo contemplou uma avaliação da formação em Psicologia a partir de uma análise documental dos resultados do Enade nas edições de 2006, 2009 e 2012 nos componentes gerais e específicos das provas. O objetivo de avaliar a formação a partir desses dados foi atingido na medida em que foram levantados pontos positivos e negativos relativamente ao desempenho dos estudantes, e algumas reflexões sobre estes.

Os resultados desses três primeiros exames realizados (respectivamente nos anos de 2006, 2009 e 2012) mostraram um aumento de IES privadas e, consequentemente, do número de vagas para o curso de Psicologia, o que implicou em mais pessoas com acesso a tal formação superior e, grande parte, com o incentivo do Governo Federal por meio do Fies. O impacto do Reuni também aparece nos relatórios do ENADE com um aumento no número de alunos das universidades públicas, o que representa um progresso, embora a maior parte da formação em Psicologia ainda esteja concentradas nas IES privadas.

Um dado positivo observado foi o aumento expressivo na participação de atividades extraclasse, notadamente nos pilares: iniciação científica, monitoria e extensão. Em 2006 e 2009, a participação em tais atividades eram incipientes; em 2012 houve um expressivo incremento da participação discente em tais atividades, com destaque para as de extensão universitária, que passou a atingir a metade dos alunos de Psicologia. Esses dados confirmaram que tais atividades podem contribuir para a formação dos estudantes.

A despeito dessa possível melhoria em termos de participação discente em atividades extraclasse, uma das principais conclusões da comparação dos resultados do Enade é a redução no desempenho dos estudantes, tanto nas universidades públicas, quanto nas privadas. $\mathrm{O}$ desempenho dos egressos no Enade de 2012 ficou abaixo da média, com uma situação ainda pior nas questões discursivas, o que pode sinalizar para uma dificuldade de realizar análises críticas referentes a temáticas do componente específico do curso. Tal resultado sinaliza para uma possível consequência para a atuação profissional em Psicologia, o que é bastante preocupante para a área.

Considerando que o Enade adota a Teoria de Resposta ao Item na pontuação das questões de múltipla escolha e que a prova é a mesma para todos os alunos, a análise comparativa de seus resultados - quer seja por região, por tipo de IES ou em termos de evolução temporal - passam a ter maior relevância. Os dados dos relatórios do Enade - relativos ao desempenho dos estudantes, mas também a outras variáveis da vida acadêmica - configuram uma avaliação produtora de múltiplos sentidos, instigando as IES a lidarem com pluralidade de pontos de vista, diversidade de sujeitos e elementos estruturais e conjunturais. É diante da complexidade desse contexto que cada uma delas precisa olhar para os resultados obtidos com a intenção de refletir sobre melhorias institucionais que reflitam na qualidade dos cursos.

Para além da crítica a ser feita por cada IES, uma análise do conjunto dos resultados do Enade - em suas diferentes edições - deve também fundamentar reflexões acerca de um projeto coletivo para repensar a formação em Psicologia, com estratégias de superação do presente. Sob essa perspectiva, estão implicados diferentes agentes sociais como o Ministério da Educação, o Conselho Federal de Psicologia em parceria com os conselhos regionais, o Sindicato dos Psicólogos e as associações científicas da área.

Merece ainda uma consideração final a análise regional dos resultados do Enade. Enquanto aconteceu uma redução no percentual de estudantes concentrados na região Sudeste, houve o crescimento de IES e de estudantes, sobretudo, nas regiões Norte e Nordeste. Essa ampliação foi positiva porque mais pessoas tiveram acesso ao ensino superior em regiões historicamente menos favorecidas. Contudo, é preciso mencionar que a região Norte apresentou o pior desempenho na avalição dos cursos, o que permite uma indagação acerca da qualidade de tal formação a despeito do aumento do número de vagas.

É também preciso destacar a preocupação com o domínio da língua portuguesa. Os dados indicam muitos erros ortográficos e dificuldades em interpretar as questões, sinalizando deficiências na educação básica. Também se questiona em que medida a redução no 
desempenho dos estudantes guarda relação com essa formação anterior. Preocupa o fato de as notas médias, em diferentes cursos e não apenas na Psicologia, estarem em queda, e ser crescente o número de alunos que percebem o exame como difícil/muito difícil.

Do ponto de vista do perfil social e demográfico, os resultados mostraram a manutenção de um perfil feminino na profissão, com uma maioria de brancos(as), mas com uma redução na renda familiar dos concluintes do curso nos últimos anos, o que traz implicações para a mudança de imagem da Psicologia como um curso elitista. Com as políticas afirmativas implantadas no país, é provável que as próximas edições do Exame apontem uma redução ainda maior na renda média dos egressos e também um incremento de estudantes não brancos, de forma a se aproximar mais da distribuição da população brasileira.

Por fim, os resultados mostram que o Enade cumpre um importante papel no sentido de alertar para pontos frágeis da formação superior no país. Especificamente para a Psicologia, há um expressivo conjunto de melhorias que precisam acontecer nas IES a fim de que se possa, de fato, ter uma formação de qualidade dos psicólogos brasileiros.

A despeito das contribuições e reflexões possibilitadas pelo presente estudo, há nele um conjunto de limitações que precisam ser consideradas. Uma dessas limitações diz respeito ao fato de os resultados estarem baseados em apenas três exames. Apesar de esse ser o número total disponível de relatórios do Enade para o curso de Psicologia (posto que a edição relativa a 2015 ainda não foi publicada), uma análise de três edições do exame ainda é pouco para que se tenha uma visão de longo prazo acerca da formação. Uma outra limitação refere-se ao fato de o presente estudo estar baseado em análise documental, uma vez que os dados dos alunos não foram disponibilizados pelo Inep. Nesse sentido, não é possível calcular estatísticas inferenciais que permitam comprovar as diferenças entre as notas das diferentes edições do exame. Os resultados limitam-se, assim, a uma análise descritiva dos dados disponibilizados nos relatórios do Inep.

Considerando tais limitações, seria importante que estudos futuros contemplassem mais edições do exame, bem como comparassem, estatisticamente, os resultados obtidos em cada uma dessas edições. Estudos complementares com egressos, docentes, coordenadores de curso, membros de associações científicas no campo da Psicologia e de outros atores, como a rede do Conselho de Psicologia e o Sindicato dos Psicólogos, também seriam úteis para se entender melhor a qualidade da formação em Psicologia e os seus impactos na sociedade.

\section{Referências}

Abbad, G. S., Mourão, L. M. (2010). Competências profissionais e estratégias de qualificação e requalificação. Em A. V. B. Bastos, \& S. M. G. Gondim (Eds.). O trabalho do psicólogo no Brasil (pp. 380-401). Porto Alegre: Artmed.

Bastos, A. V. B., Gondim, S. M. G., \& Rodrigues, A. C. A. (2010). Uma categoria profissional em expansão: Quantos somos e onde estamos? Em A. V. B. Bastos, \& S. M. G. Gondim (Eds.), O trabalho do psicólogo no Brasil (pp. 32-44). Porto Alegre: Artmed.

Bertolin, J. C. G. (2009). Qualidade em educação superior: Da diversidade de concepções a inexorável subjetividade conceitual. Avaliação, 14(1), 127-149.

Brito, M. R. F. (2008). O Sinaes e o Enade: Da concepção à implantação. Avaliação, 13(3), 841-850.

Castro, M. H. M. (1995). Avaliação institucional para a autogestão: Uma proposta. Ensaio: Avaliação de Políticas Públicas em Educação, 3(7), 157-172.

Conselho Federal de Psicologia (1988). Quem é o psicólogo brasileiro? São Paulo: Edicon. Recuperado de http://newpsi.bvs-psi.org.br/ ebooks2010/en/Acervo_files/QuemPsicologoBrasileiro.pdf

Embiruçu, M., Fontes, C. \& Âlmeida, L. (2010). Um indicador para a avaliação do desempenho docente em instituições de ensino superior. Ensaio: Avaliação de Políticas Públicas em Educação, 18(69), 795-820.

Fiamini, C., \& Calderón, A. I. (2012). Exame Nacional de Desempenho de Estudantes (Enade): Uma análise à luz da cobertura da Folha de São Paulo (2003-2010). Revista FUNADESP, 5(5), 91-114.

IBGE - Instituto Brasileiro de Geografia e Estatística - IBGE (2012). Centro de Processamento SIRGAS IBGE. Recuperado de http://www. ibge.gov.br/home/geociências/geodesia/centros_apres.shtm, último acesso: 20/09/2015

INEP - Instituto Nacional de Estudos e Pesquisas Educacionais Anísio Teixeira. (2015). Relatórios do Exame Nacional de Desempenho de Estudantes - Curso de Psicologia. Recuperado de http://portal.inep.gov.br/relatorios

Gomes, A. M. (2002). Política de avaliação da educação superior: Controle e massificação. Educação e Sociedade, 23(80), $275-298$.

Guareschi, N. M. de F., Wendt, G. W., \& Dhein, G. (2011). As atividades de pesquisa, extensão e monitoria na formação em psicologia. Avaliação Psicológica, 10(3), 387-403.

Lima, E. E., \& Machado, L. R. de S. (2016). Reuni e Expansão Universitária na UFMG de 2008 a 2012. Educação E Realidade, 41 (2), $383-406$. doi: 10.1590/2175-623654765

Lisboa, F. S. \& Barbosa A. J. G. (2009). Formação em Psicologia no Brasil: Um perfil dos cursos de graduação. Psicologia Ciência e Profissão, 29(4), 718-737.

Molck, A. M., \& Calderón, A. I. (2014). Exame Nacional de Desempenho de Estudantes: mapeamento e tendências temáticas da produção científica brasileira (2004 -2010). Educação On-Line (PUC-Rio), 15, 57-77.

Polidori, M. M., Marinho-Araujo, C. M. \& Barreyro, G. B. (2006) SINAES: Perspectivas e desafios na avaliação da educação superior brasileira. Ensaio: Avaliação de Políticas Públicas em Educação, 14(53). 
Primi, R., Hutz, C. S., \& Silva, M. C. R. da. (2011). A prova do Enade de Psicologia 2006: Concepção, construção e análise psicométrica da prova. Avaliação Psicológica, 10(3), 271-294.

Puente-Palacios, K. E., Abbad, G. S., \& Martins, M. D. C. (2010). Imagem da profissão e perspectivas futuras. Em A. V. B. Bastos, \& S. M. G. Gondim (Eds). O trabalho do psicólogo no Brasil (pp. 402-418). Porto Alegre: Artmed.

Santos, M. A. P., Souza, B. F. de, Basso, I., Luchesi, D., Zambelo, E. A., \& Bosqui, R. H. (2016). O impacto das avaliações disciplinares no ensino superior. Avaliação: Revista da Avaliação da Educação Superior (Campinas), 21(1), 247-261. doi: 10.1590/S1414-40772016000100012

Saviani, D. (2011). A expansão do ensino superior no Brasil: Mudanças e continuidades. Poíesis Pedagógica, 8(2), 4-17. doi: 10.5216/rpp. v8i2.14035.

Silva, A. C. \& Silva, C. M. T. (2009). Do diagnóstico às questões avaliativas: Um caminho possível via prática de avaliação em educação a distância. Ensaio: Avaliação de Políticas Públicas em Educação, 17(63), 293-312.

Sobrinho, J. D. (2008) Qualidade, avaliação: do SINAES a índices. Avaliação, 13(3), 817-825.

Souza, M. P. R., Bastos, A. V., \& Barbosa, D. R. (2011). Formação básica e profissional do psicólogo: análise do desempenho dos estudantes no Enade-2006. Avaliação Psicológica, 10(3), 295-312.

Souza, A. M. L. (2012). Avaliação da aprendizagem no ensino superior: Aspectos históricos. Revista Exitus, 2(1), 231-254.

Tavares, M. G. M., Oliveira M. A. A., \& Seiffert, O. M. L. B. (2011). Avaliação da educação superior na revista ensaio: Avaliação e políticas públicas em educação - Ênfases e tendências. Ensaio: Avaliação de Políticas Públicas em Educação,19(71), 233-258.

Tumolo, L. M. S. O. (2010). Enade como processo de autoavaliação dos cursos de graduação e da instituição. Cadernos Acadêmicos, 2(2),1-14.

Vendramini, C. M. M., \& Lopes, F. L. (2016). Desempenho no Enade de bolsistas ProUni: Modelagem de equações estruturais. Fractal: Revista de Psicologia, 28(1), 69-75. doi:10.1590/1984-0292/1040

Verhine, R. E., Dantas, L. M. V., \& Soares, J. F. (2006). Do Provão ao Enade: Uma análise comparativa dos exames nacionais utilizados no Ensino Superior Brasileiro. Ensaio: Avaliação de Políticas Públicas em Educação, 14(52), 291-310.

Yamamoto O. H., Falcão J. T. R., \& Seixas P. S. (2011). Quem é o estudante de Psicologia do Brasil? Avaliação Psicológica, 10(3), $209-232$.

\section{Sobre os autores}

Rômulo Travassos é Doutor em Psicologia, Professor da Universidade Estadual do Maranhão, São Luís-MA.

Luciana Mourão é Doutora em Psicologia, Professora do Programa de Pós-Graduação em Psicologia da Universidade Salgado de Oliveira, Niterói-RJ. 